Check for updates

Cite this: RSC Adv., 2017, 7, 43356

Received 27th July 2017

Accepted 25th August 2017

DOI: $10.1039 / c 7 r a 08275 d$

rsc.li/rsc-advances

\section{Winter-jujube-derived carbon with self-doped heteroatoms and a hierarchically porous structure for high-performance supercapacitors}

\author{
Yuanyuan Li, (D) Kaiwen Zheng, Sayyed Asim Ali Shah, Yizhou Huang, Yazhou Tian, \\ Jue Cheng* and Junying Zhang*
}

Novel biomass-derived carbon materials have attracted a lot of attention for application in supercapacitors due to their low cost and environmental friendly properties. Herein, we report a novel winter-jujube-derived carbon material (JC) prepared via a pre-carbonization and $\mathrm{KOH}$ activation strategy. The physical and chemical properties of JC were characterized by field-emission scanning electron microscopy (FESEM), X-ray photoelectron spectroscopy (XPS), X-ray diffraction (XRD), Raman spectroscopy, and nitrogen adsorption-desorption isotherms. The electrochemical characteristics are measured using cyclic voltammetry (CV), galvanostatic charge-discharge (GCD), and electrochemical impedance spectroscopy (EIS). The as-obtained carbon skeleton possesses a hierarchical porous structure, abundant heteroatom groups, and good electrical conductivity. It is notable that the use of $\mathrm{KOH}$ significantly influenced the properties of JC. When the $\mathrm{KOH}$ to carbon weight ratio is $3.5: 1$, the as-prepared sample (JC-3.5) possesses an ultra-huge specific surface area (SSA) of $2286.2 \mathrm{~m}^{2} \mathrm{~g}^{-1}$. In addition, the electrochemistry results show that $\mathrm{JC}-3.5$ exhibits a high specific capacitance up to $341 \mathrm{~F} \mathrm{~g}^{-1}$ at $0.5 \mathrm{~A} \mathrm{~g}^{-1}$ and a considerable rate capability of $76 \%$ retention when the current density increases to $20 \mathrm{~A} \mathrm{~g}^{-1}$. After 5000 cycles at $5 \mathrm{~A} \mathrm{~g}^{-1}$, the capacitance still has $96.5 \%$ retention. In addition, the JC-3.5-based symmetric supercapacitor device possesses an energy density of $30.9 \mathrm{~kW} \mathrm{~h}^{-1}$ at $0.1 \mathrm{~A} \mathrm{~g}^{-1}$ and power density of $8.9 \mathrm{~kW}$ at $5 \mathrm{~A} \mathrm{~g}^{-1}$. Therefore, it is quite feasible to make the winter-jujube-derived carbon material into a high performance supercapacitor electrode material.

\section{Introduction}

Since the 21st century, the global economy has continued to develop rapidly. At the same time, mankind has made great progress in technology and the quality of life, which has resulted in the increased consumption of resources and serious environmental pollution. There is an urgent need for green, efficient, renewable and advanced energy storage devices and conversion technologies. Currently, lithium ion batteries have gained a lot of attention as a new storage device of secondary batteries ${ }^{1-6}$ However, the low power density and short charge and discharge life limit the applications of lithium-ion batteries. Supercapacitors, as new energy storage devices among traditional capacitors and batteries, have attracted more and more attention due to their high power density, short charging time, long cycle life, wide operating temperature range, and environmental friendly characteristics. ${ }^{7-15}$ However, unsatisfactory capacitance is the biggest drawback of most

The Key Laboratory of Beijing City on Preparation and Processing of Novel Polymer Materials, Beijing University of Chemical Technology, Beijing 100029, China. E-mail: chengjue@mail.buct.edu.cn; zhangjy@mail.buct.edu.cn; Fax: +86 106442 5439; Tel: +861064425439 commercial supercapacitors. ${ }^{16}$ In order to provide a continuous energy supply, it is necessary to improve the capacitance of a supercapacitor.

There are various ways to improve the capacitance of supercapacitors, and the key issue is the selection and preparation of the electrode materials. ${ }^{17}$ Currently, there are two main types of supercapacitors namely faradaic pseudocapacitors, and electric double-layer supercapacitors (EDLCs), which possess different electrode materials. Faradaic pseudocapacitors are composed of transition metal oxide or conductive macromolecule electrodes and usually have a large capacitance. However, as the chemical reactions proceed, there are often irreversible components involved in the electrode reaction, resulting in poor cycling stability. The electrodes of double-layer supercapacitors (EDLCs) are usually constructed from porous activated carbon. The physical energy storage process makes its cycling stability very good. However, their capacitance still needs improvement. ${ }^{16}$

It is an important task to combine the advantages of these two supercapacitors, such as the higher energy density and cycling stability. One method is to use an asymmetric hybrid supercapacitor system, that is, one electrode using activated carbon and the other electrode using a pseudo-capacitance 
electrode material or battery electrode material. Another way is to increase the capacitance of the supercapacitor electrode materials, and researchers have carried out a lot work in this area. $\mathrm{Mu}$ et al. dispersed $\mathrm{Fe}_{3} \mathrm{O}_{4}$ nanosheets onto onedimensional (1D) carbon nanofibers (CNFs) via an electrospinning technique and solvent-thermal process. ${ }^{18}$ Zhang et al. prepared graphene and polyaniline (PANI) nanofiber composites via the in situ polymerization of an aniline monomer in the presence of graphene oxide under acidic conditions. ${ }^{19}$ However, the preparation of carbon materials such as graphene, carbon fibers and carbon nanotubes is always very complex. In addition, the high cost is the biggest drawback for their practical application. In addition, the preparation processes are not environment friendly.

Biomass carbon materials, which are easily accessible, renewable, sustainable and environment friendly, can be simply prepared using carbonization or pyrolysis. Biomass materials usually have an ordered structure, and $\mathrm{KOH}$-activated biomass carbon material can have an ultra-high specific surface area. Moreover, the considerable heteroatom self-doping (such as $\mathrm{N}$, $\mathrm{O}$, and $\mathrm{P}$ ) makes it a great candidate for supercapacitor electrode materials. Currently, various types of biomass materials have been used as carbon materials. ${ }^{20-23}$ Huang et al. produced activated carbon fibers from recycled fir sawdust using steam$\mathrm{KOH}$ reactivation. ${ }^{24}$ Its specific capacitance is $242 \mathrm{~F} \mathrm{~g}^{-1}$ at $0.5 \mathrm{~A} \mathrm{~g}^{-1}$ due to its mediocre structure and poor heteroatom content. Liang et al. synthesized a three-dimensional (3D) honeycomb-like porous carbon (HLPC) using the simple carbonization of pomelo peel. ${ }^{25}$ The excellent porous structure provides HLPC a high specific capacitance up to $342 \mathrm{~F} \mathrm{~g}^{-1}$ at $0.2 \mathrm{~A} \mathrm{~g}^{-1}$. However, the low heteroatom content hinders its capacitance from being enhanced. Wei et al. made $\mathrm{NiCo}_{2} \mathrm{O}_{4}$ nanowires grow on a mollusc shell-based macroporous carbon material (MSBPC). ${ }^{26}$ The obtained $\mathrm{NiCo}_{2} \mathrm{O}_{4} / \mathrm{MSBPC}$ composites showed a ultra-high specific capacitance up to $1696 \mathrm{~F} \mathrm{~g}^{-1}$ at $1 \mathrm{~A} \mathrm{~g}^{-1}$; however, the major drawback is external doping, which limits the cycling stability (12\% capacitance loss after 2000 cycles) and rate capability $(24.9 \%$ capacitance remained at $50 \mathrm{~A} \mathrm{~g}^{-1}$ ). For the purpose of improving the comprehensive performance of supercapacitors, we need materials that possess considerable self-doped heteroatoms and excellent hierarchical porous structures with large specific surface areas.

Winter-jujube is an abundant and renewable source with plenty of $\mathrm{O}, \mathrm{N}$ and trace elements. In this study, winter-jujubederived carbon materials (JC) were prepared via a precarbonization and $\mathrm{KOH}$ activation process. This activated carbon possesses abundant heteroatom ( $\mathrm{O}$ and $\mathrm{N}$ ) groups. These groups give JC good electrical conductivity and enable JC to not only provide electrical double-layer capacitance, but also faradaic pseudocapacitance, which combines the contributions from EDLCs and faradaic pseudocapacitors. In addition, $\mathrm{KOH}$ activation gave JC an excellent hierarchically porous structure. When the $\mathrm{KOH}$ to carbon weight ratio was $3.5: 1$, the asprepared sample (JC-3.5) possessed an ultra-high specific surface area of $2286.2 \mathrm{~m}^{2} \mathrm{~g}^{-1}$ and a high capacitance up to $341 \mathrm{~F} \mathrm{~g}^{-1}$ at $0.5 \mathrm{~A} \mathrm{~g}^{-1}$. It is quite promising to make JC a candidate carbon source to fabricate biomass-derived carbon based supercapacitors. In addition, the application of this green resource in supercapacitors is also beneficial for environmental protection and energy demand.

\section{Experimental}

\subsection{Materials}

Fresh winter-jujubes were purchased from a local fruit store. The producing place was the Shandong Province of China. The winterjujubes were washed clean before use without further treatment. $\mathrm{KOH}$ and $\mathrm{HCl}$ solution were provided by Beijing Chemical Work.

\subsection{Preparation of winter-jujube-derived carbon (JC)}

JC was prepared using a pre-carbonization and $\mathrm{KOH}$ activation strategy. In a typical process, a few winter-jujubes were first freezedried using a lyophilizer for about three days. Then, the dry winter-jujubes were placed in a corundum boat to be precarbonized in a tube furnace. The pre-carbonization temperature was $400{ }^{\circ} \mathrm{C}$ at a heating rate of $5{ }^{\circ} \mathrm{C} \mathrm{min}{ }^{-1}$ under a flow of $\mathrm{N}_{2}$. The resulting black solid block material was then mixed with a $\mathrm{KOH}$ aqueous solution in a beaker with a magnetic stirrer. After that, the black mixture was heated to $120{ }^{\circ} \mathrm{C}$ until water was removed. Then, the remaining black solid was placed in the tube furnace again to be carbonized. With the protection of $\mathrm{N}_{2}$, the procedures were as follows: it was first heated to $450{ }^{\circ} \mathrm{C}$, and this temperature was held for 30 minutes; then, the temperature was increased up to $650{ }^{\circ} \mathrm{C}$ and held for another 30 minutes; finally, the temperature was increased to $800^{\circ} \mathrm{C}$ and held for 1 hour. After the carbonization procedure, the sample was cooled naturally under a flow of $\mathrm{N}_{2}$. Hydrochloric acid solution was used to remove the impurities produced during the carbonization step and the $\mathrm{pH}$ of the mixture was adjusted to be weakly acidic. The resulting mixture was enclosed carefully in a dialysis bag. Then, the bag was immersed into deionized water to remove the impurities. A series of samples with different ratios of $\mathrm{KOH}$ to carbon weight were prepared to investigate the effect of $\mathrm{KOH}$ on the microstructure and electrochemical performance of the as-prepared JC. We chose varying $\mathrm{KOH}$ to carbon weight ratios of $1.5: 1,2.5: 1$, $3.5: 1$ and $4.5: 1$, and the corresponding JC samples were named as JC-1.5, JC-2.5, JC-3.5 and JC-4.5, respectively.

\subsection{Characterization}

The morphology of the pre-carbonized and $\mathrm{KOH}$-activated winter-jujube was analyzed via field-emission scanning electron microscopy (FESEM, Hitachi S-4800). The structure of JC was investigated using wide-angle X-ray diffraction (WXRD, D/ MAX-2500, Rigaku Co.) with $2 \theta$ values of $5-90^{\circ}$ at a scanning rate of $5^{\circ} \min ^{-1}$ and Raman spectroscopy (inVia Reflex, Renishaw Co.) with an excitation wavelength of $532 \mathrm{~nm}$. X-ray photoelectron spectroscopy was performed on a ThermoFisher Scientific Escalab 250 using a monochromatic Al Ka source. The porous structure was measured using nitrogen adsorption and desorption isotherms on a JWGB SCI. \& TECH. Co. BK200C analyzer. The specific surface area (SSA) was calculated using the Brunauer-Emmet-Teller (BET) equation. The pore-size distribution (PSD) was obtained using the 
Horvath-Kawazoe (HK) method $(<2 \mathrm{~nm})$ and the Barrett-Joyner-Halenda $(\mathrm{BJH})$ method $(>2 \mathrm{~nm})$ using the nitrogen adsorption data. Galvanostatic discharge-charge and cyclic stability tests were performed on a Land ct2001a supercapacitor tester. Cyclic voltammetry (CV) and impedance spectroscopy (EIS) were measured on an electrochemical workstation from Autolab PGSTAT 302N, Metrohm, Netherlands. A standard three-electrode system in $1 \mathrm{~mol} \mathrm{~L}^{-1} \mathrm{H}_{2} \mathrm{SO}_{4}$ aqueous solution was adopted for the electrochemical test. The working electrode was a mixture of JC and poly(vinylidene fluoride) (PVDF) at a mass ratio of $9: 1$ smeared on a platinum foil. The reference electrode was an $\mathrm{Ag} / \mathrm{AgCl}$ electrode, and the counter electrode was a blank platinum foil. Two-electrode system (supercapacitors device) tests were conducted in $1 \mathrm{~mol} \mathrm{~L}^{-1} \mathrm{H}_{2} \mathrm{SO}_{4}$ aqueous solution with two nearly identical (by weight and size) JC electrodes and a porous polymeric separator permeable to ion transport. The specific capacitance $\left(C_{\mathrm{s}}\right)$ based on the GCD measurement was calculated using the following equation:

$$
C_{\mathrm{s}}=\frac{I \times \Delta t}{\Delta V \times m}
$$

where $I$ (A) is the charge/discharge current, $\Delta t(\mathrm{~s})$ is the discharge time, $\Delta V(\mathrm{~V})$ is the voltage change excluding the $I R$ drop during the discharge process, and $m(\mathrm{~g})$ is the mass of active material.

The energy density ( $\left.E, \mathrm{~W} \mathrm{~h} \mathrm{~kg}^{-1}\right)$ and power density $\left(P, \mathrm{~W} \mathrm{~kg}^{-1}\right)$ were calculated using the following equations:

$$
\begin{gathered}
E=\frac{1}{2} C_{\mathrm{s}} \Delta V^{2} \\
P=\frac{E}{\Delta t}
\end{gathered}
$$

where $C_{\mathrm{s}}\left(\mathrm{F} \mathrm{g} \mathrm{g}^{-1}\right)$ is the specific capacitance of the JC supercapacitors, $\Delta V(\mathrm{~V})$ is the voltage change excluding the $I R$ drop during the discharge process, and $\Delta t(\mathrm{~s})$ is the discharge time.

\section{Results and discussion}

Fig. 1 shows the surface morphology of the pre-carbonized (Fig. 1a-c) and $\mathrm{KOH}$ activated winter-jujube (Fig. 1d-g).
Despite using different $\mathrm{KOH}$-carbon weight ratios, each sample displayed a similar morphology. Fig. 1a is the microstructure of the pre-carbonized winter-jujube. It demonstrates that abundant micrometer pores exist in the JC structure (ranging from 20 to $100 \mu \mathrm{m}$ ), which may be attributed to the inherent property of winter-jujube. Upon further magnification, it revealed smaller pores sized a few tenths to a $1 \mu \mathrm{m}$ (Fig. 1b) inside of the abovementioned large pores. In addition, Fig. 1c reveals that the margin and interior of the pores are smooth. After the $\mathrm{KOH}$ activation process, plenty of new micropores appeared (Fig. 1d-g), which indicated that the specific surface area of JC had increased. To confirm this assumption, the pore properties of JC were determined using nitrogen adsorption and desorption measurements. Fig. 2a shows the adsorption-desorption isotherms for all four JC samples. The typical hysteresis loop at $P / P_{0}>0.4$ in each sample indicates a combination of Type I and IV isotherms, which indicate the existence of micropores and mesopores. Moreover, the slight rise in high relative pressure $\left(P / P_{0}=0.95-1.0\right)$ and the sharp rise in low relative pressure $\left(P / P_{0}=0.01\right)$ revealed the presence of macropores and

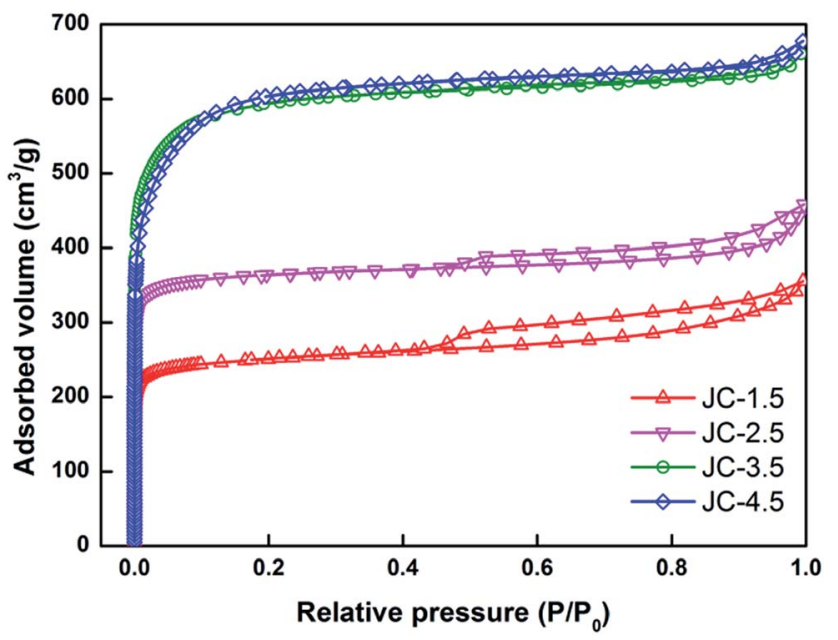

Fig. 2 The nitrogen adsorption-desorption isotherms of the JC-1.5, JC-2.5, JC-3.5 and JC-4.5 samples.

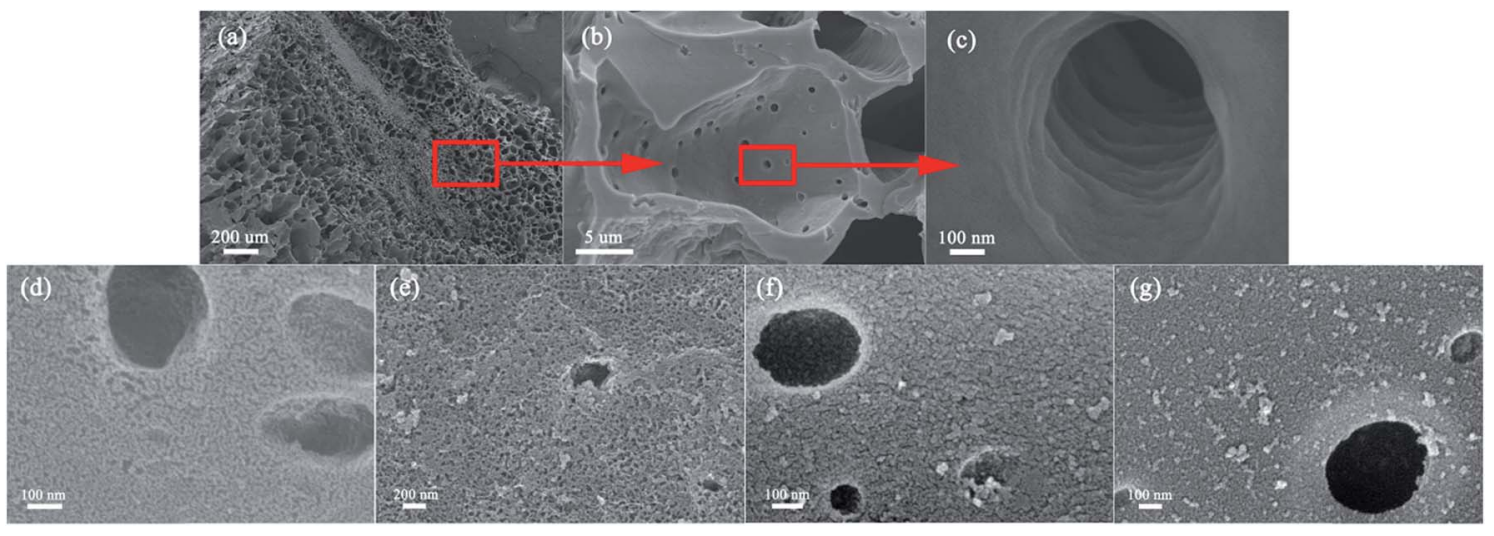

Fig. 1 SEM images of pre-carbonized winter-jujube (a-c) and KOH activated JC-1.5 (d), JC-2.5 (e), JC-3.5 (f) and JC-4.5 (g). 

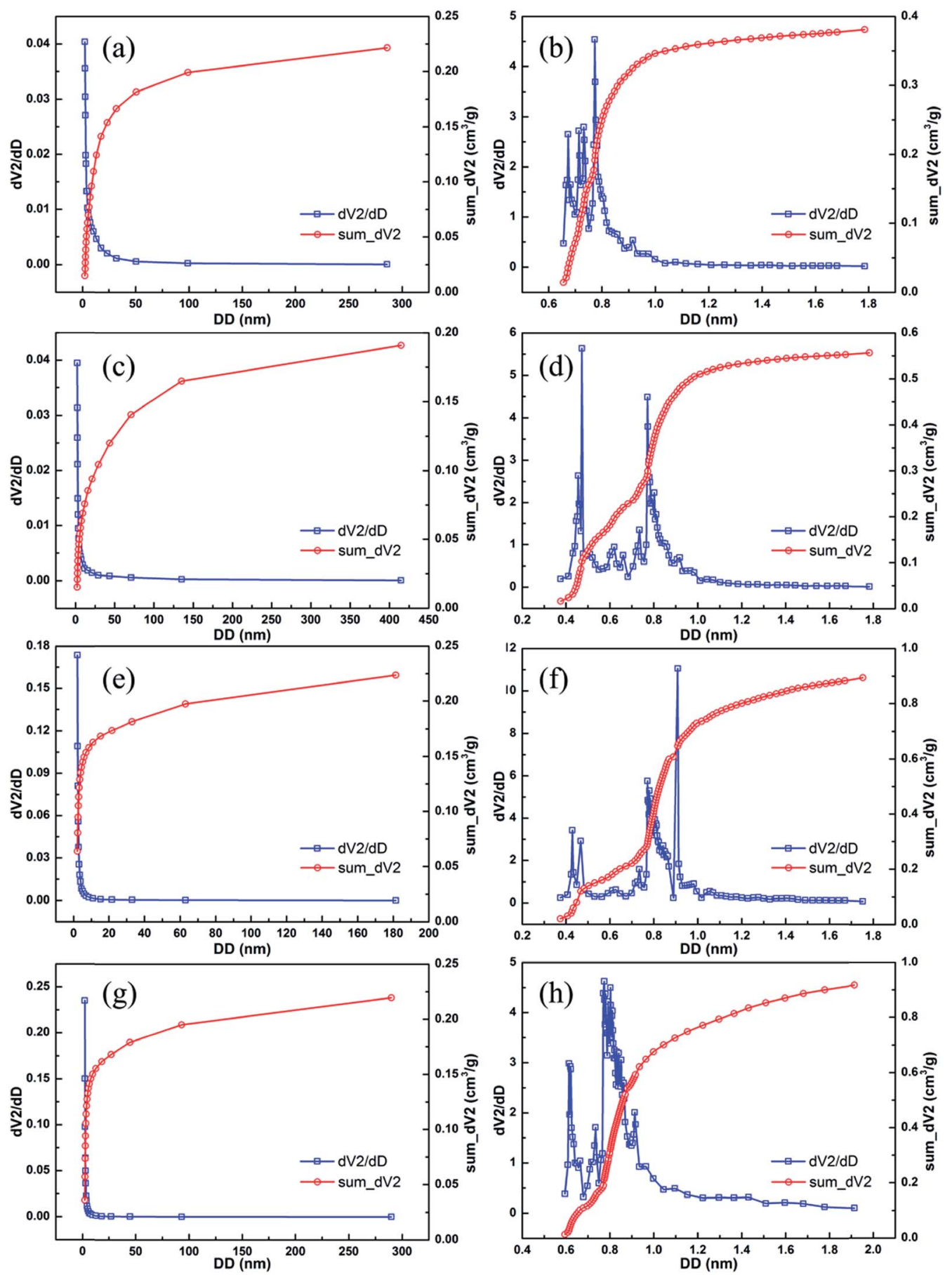

Fig. 3 The pore size distribution and integration in the pore-size ranges of $0-2 \mathrm{~nm}$ and $2-400 \mathrm{~nm}$ of the JC-1.5 (a and b), JC-2.5 (c and d), JC3.5 (e and f) and JC-4.5 (g and h) samples.

micropores, respectively. ${ }^{27-29}$ Fig. 3 shows the pore size distribution of JC. From Fig. 3, we can see the existence of micropores (less than $2 \mathrm{~nm}$ ), mesoporous (2-50 nm), and macropores (more than $50 \mathrm{~nm}$ ). These various pores constitute a hierarchically porous structure and significantly improve the electrolyte contact and accumulation of electrolyte ions. ${ }^{28,30}$ Table 1 shows the specific surface area and pore structure parameters of the samples, which confirm that $\mathrm{KOH}$ makes a vital contribution to the formation of the pore structure. For these several samples, the SSA increased along with the consumption of KOH. JC-3.5 and JC-4.5 both reveal an ultra-high BET surface area of $2286.2 \mathrm{~m}^{2} \mathrm{~g}^{-1}$ and $2303.2 \mathrm{~m}^{2} \mathrm{~g}^{-1}$, respectively. This also shows that an excess $\mathrm{KOH}$ does not offer further assistance towards pore formation.

Further information on the structure of JC was obtained from X-ray diffraction (XRD) and Raman spectroscopy. The XRD 
Table 1 The SSA and pore structure parameters of the JC-1.5, JC-2.5, JC-3.5 and JC-4.5 samples

\begin{tabular}{lllll}
\hline Sample & $\begin{array}{l}\text { BET SSA } \\
\left(\mathrm{m}^{2} \mathrm{~g}^{-1}\right)\end{array}$ & $\begin{array}{l}\text { Average pore } \\
\text { width }(\mathrm{nm})\end{array}$ & $\begin{array}{l}\text { Pore volume } \\
\left(V_{\text {total }}, \mathrm{cm}^{3} \mathrm{~g}^{-1}\right)\end{array}$ & $\begin{array}{l}\text { Micropore } \\
\text { volume }\end{array}$ \\
\hline JC-1.5 & 987 & 2.227 & 0.550 & 0.381 \\
$\mathrm{JC}-2.5$ & 1463 & 1.937 & 0.709 & 0.557 \\
JC-3.5 & 2286 & 1.787 & 1.021 & 0.895 \\
JC-4.5 & 2303 & 1.820 & 1.048 & 0.917 \\
\hline
\end{tabular}

pattern (Fig. 4a) of JC-1.5 shows two weak and broad peaks around $2 \theta=21$ and $43.5^{\circ}$, which correspond to the (002) and (100) planes diffraction of graphitic carbon. The broader peak around $21^{\circ}$ was attributed to the amorphous carbon structure, which contributed to the high SSA. In addition, a large increase appears in the low angle area and confirms the microporous structure. ${ }^{31}$ The weak peak located at $43^{\circ}$ suggests the existence of a graphitic-type carbon structure in JC. The intensity of the two peaks decreases with an increase in $\mathrm{KOH}$, which reveals that an excess amount of $\mathrm{KOH}$ destroys the structure of JC. Simultaneously, the slight shift in the location of the (002) diffraction peaks also indicates the differences in the constituents of the four samples. The Raman spectra, shown in Fig. 4b, show two well-known peaks in carbon materials, which are the D-band located around $1339 \mathrm{~cm}^{-1}$ and G-band around $1589 \mathrm{~cm}^{-1}$. In addition, the D-band represents the defects and disordered structure, while the G-band reveals the existence of graphitic structure in the material..$^{32}$ As an indicator of the degree of graphitization, the $\mathrm{D} / \mathrm{G}$ intensity ratios approximating to 1 reveal the amorphous characteristics of JC, which are beneficial for the conduction of electrons. The XRD and Raman results are consistent with the SEM results.
Table 2 The elemental composition of the JC-1.5, JC-2.5, JC-3.5, and JC-4.5 samples

\begin{tabular}{llll}
\hline & \multicolumn{2}{l}{ XPS (at\%) } & \\
\cline { 2 - 4 } Sample & C & O & N \\
\hline JC-1.5 & 77.8 & 21.1 & 1.1 \\
JC-2.5 & 73.0 & 25.6 & 1.3 \\
JC-3.5 & 74.9 & 23.9 & 1.2 \\
JC-4.5 & 73.5 & 24.9 & 1.6 \\
\end{tabular}

Furthermore, XPS was used to identify the elemental composition and surface functional groups of the assynthesized JC. The results of the survey spectra (Fig. 4c) confirm that the main components of JC are $\mathrm{C}, \mathrm{O}$, and $\mathrm{N}$ on account of incomplete carbonization. The specific compositions are shown in Table 2. Fig. $4 \mathrm{f}$ shows the $\mathrm{C} 1$ high resolution spectrum of JC-3.5. The four peaks at $284.6 \mathrm{eV}, 285.2 \mathrm{eV}$, $286.3 \mathrm{eV}$, and $288.9 \mathrm{eV}$ correspond to $\mathrm{C}-\mathrm{C}, \mathrm{C}-\mathrm{N}, \mathrm{C}-\mathrm{O}$ and $\mathrm{COO}$, respectively. ${ }^{33}$ The spectra observed for the three other samples are shown in Fig. 4. The XPS results verify the existence of $\mathrm{O}$ and $\mathrm{N}$, and these heteroatoms can process faradaic reactions and increase the pseudo-capacitance.

To evaluate the electrochemical performance of the asprepared JC applied in a supercapacitor, cyclic voltammetry (CV) and galvanostatic charge/discharge (GCD) measurements were conducted. Fig. 5 shows the CV curves of JC at different scan rates. The shapes of the $\mathrm{CV}$ curves are quasi-rectangular, demonstrating that JC behaves as an electrical double-layer capacitor with fast charge/discharge processes. In addition, the rapid growth of current appearing in the switching potential indicates an excellent mass-transfer ability. This is ascribed to the hierarchically porous structure shown in the pore size distribution. As we can see clearly in Fig. 6, the curve
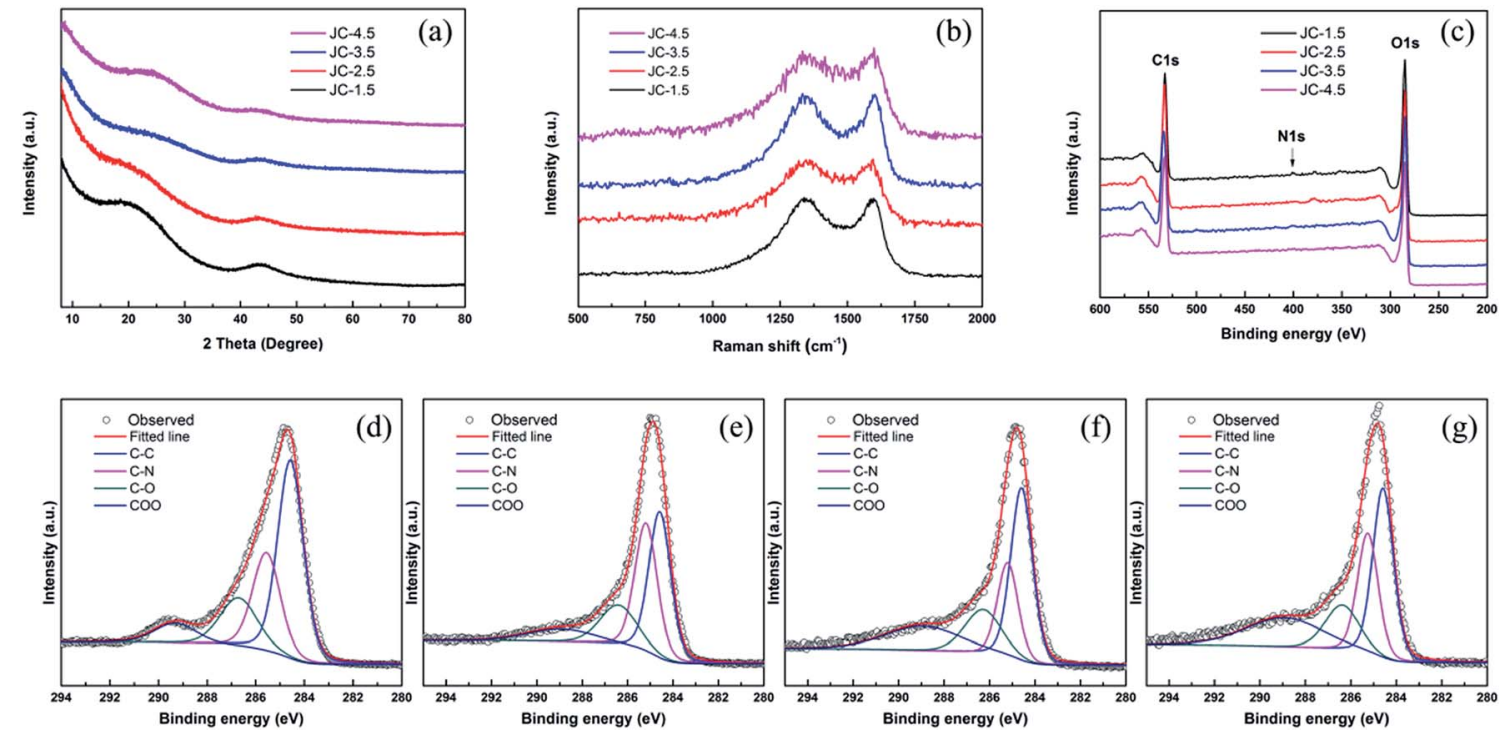

Fig. 4 The XRD pattern (a), Raman spectra (b) and XPS spectra (c) of the JC-1.5, JC-2.5, JC-3.5 and JC-4.5 samples. The C1 high-resolution XPS spectra of the JC-1.5 (d), JC-2.5 (e), JC-3.5 (f) and JC-4.5 (g) samples. 

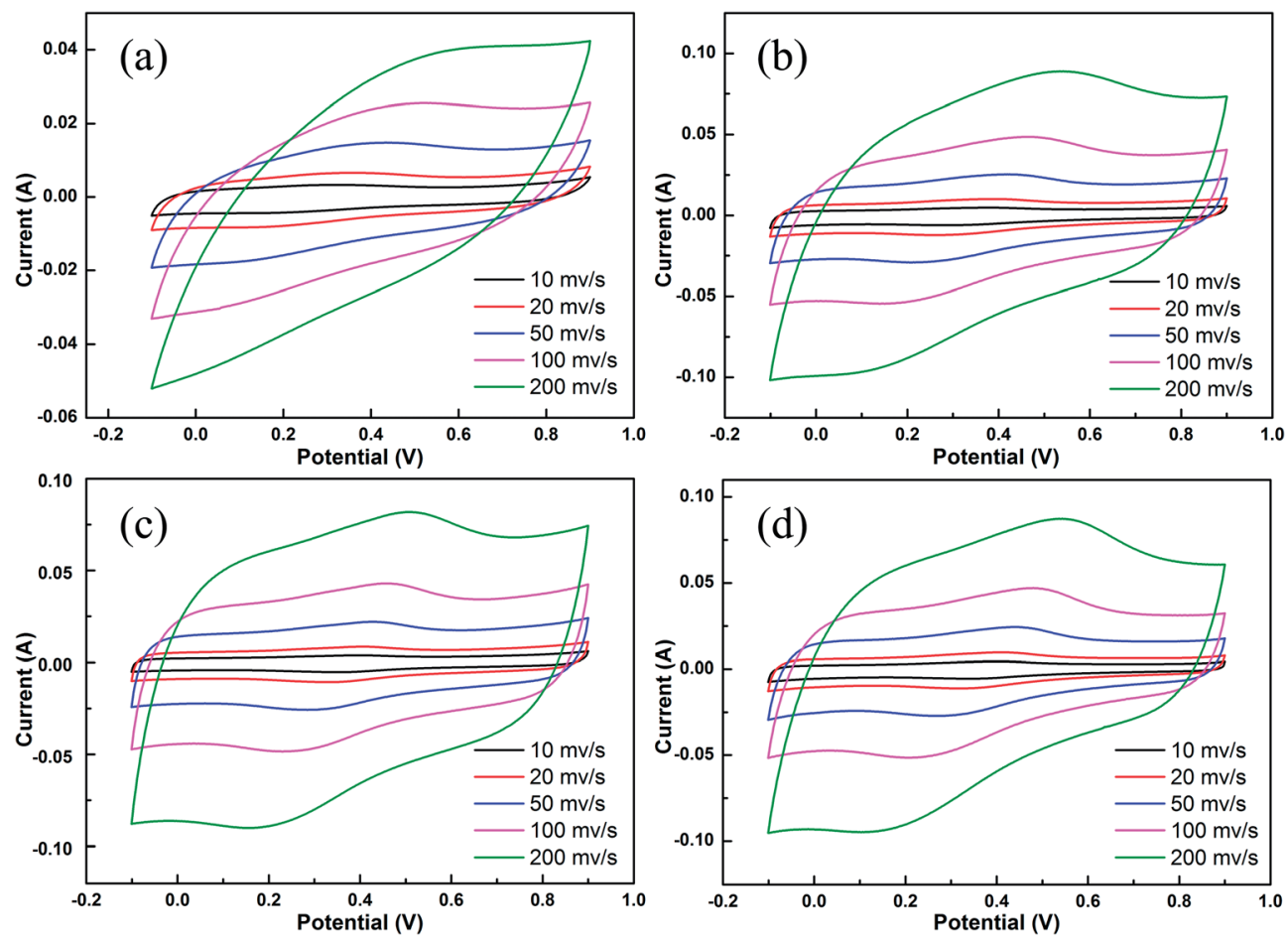

Fig. 5 The CV curves obtained for the JC-1.5 (a), JC-2.5 (b), JC-3.5 (c) and JC-4.5 (d) samples.

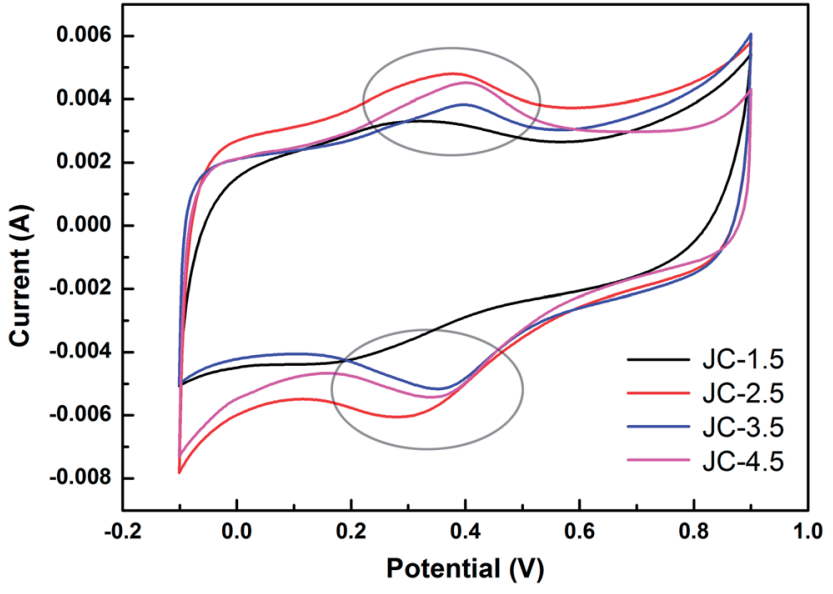

Fig. 6 The CV curves obtained at $10 \mathrm{mV} \mathrm{s}^{-1}$ for the JC-1.5, JC-2.5, JC-3.5 and JC-4.5 samples.

at $10 \mathrm{mV} \mathrm{s}^{-1}$ scan rate, a redox reaction caused current increasing appears around $0.3 \mathrm{~V}$ in the $\mathrm{CV}$ curves. This was ascribed to the $\mathrm{N}$ and $\mathrm{O}$ functional groups on the surface, which were determined by the XPS spectra. Fig. 7 displays all the galvanostatic charge-discharge curves within a potential range of -0.1 to $0.9 \mathrm{~V}$ at different current densities. All of the curves possess a nearly perfect symmetrical triangular shape except a slight deformation. This suggests an electrical double layer capacitance characteristic combined with the existence of pseudocapacitive behavior, which is consistent with the conclusion of $\mathrm{CV}$.
Fig. 8a summarizes the specific capacitances calculated from the $\mathrm{CV}$ curves and the influence of the current density to the specific capacitance of JC. The curve shows that the highest specific capacitance was up to $233,274,341$ and $333 \mathrm{~F} \mathrm{~g}^{-1}$ at a current density of $0.5 \mathrm{~A} \mathrm{~g}^{-1}$ for the JC-1.5, JC-2.5, JC-3.5 and JC4.5 samples, respectively. The capacitance increases with an increase in the amount of $\mathrm{KOH}$. When the $\mathrm{KOH}$-carbon ratio was $3.5: 1$, the capacitance reached its highest value. Further increasing the amount of $\mathrm{KOH}$ did not increase the capacitance. When the current density was increased to $20 \mathrm{~A} \mathrm{~g}^{-1}$, the capacitance was still retained at 155, 225, 260, and $250 \mathrm{~F} \mathrm{~g}^{-1}$ with $66.5,82.1,76.2$, and 75.1\% retention, respectively. Moreover, the charge-discharge cycle stability was also investigated at a current density of $5 \mathrm{~A} \mathrm{~g}^{-1}$ for 5000 cycles, and the results are shown in Fig. 8b. After the process, there was still 96.6, 98.8, 96.5, and 96.9\% capacitance retention for JC-1.5, JC-2.5, JC-3.5 and JC-4.5, respectively, indicating their excellent cycling stability. Table 3 lists the properties of other biomass-derived carbon materials with JC as a comparison, which indicates the excellent rate capability and specific capacitance of JC. ${ }^{34-37}$

Electrochemical impedance spectroscopy (EIS) was performed (Fig. 8c and d). A classical Nyquist plot was also obtained in a $1 \mathrm{M} \mathrm{H}_{2} \mathrm{SO}_{4}$ aqueous electrolyte using a three-electrode system. The frequency was investigated from $10^{-2}$ to $10^{5} \mathrm{~Hz}$. The Nyquist plots obtained for JC-2.5, JC-3.5, and JC-4.5 show nearly vertical lines in the low-frequency region, which corresponds to ideal capacitive behavior. Moreover, the $45^{\circ}$ slope, which represents the ion diffusion ability, is very short to obtain efficient access of the electrolyte ions to the electrode. Corresponding to displaying the highest specific capacitance, sample 

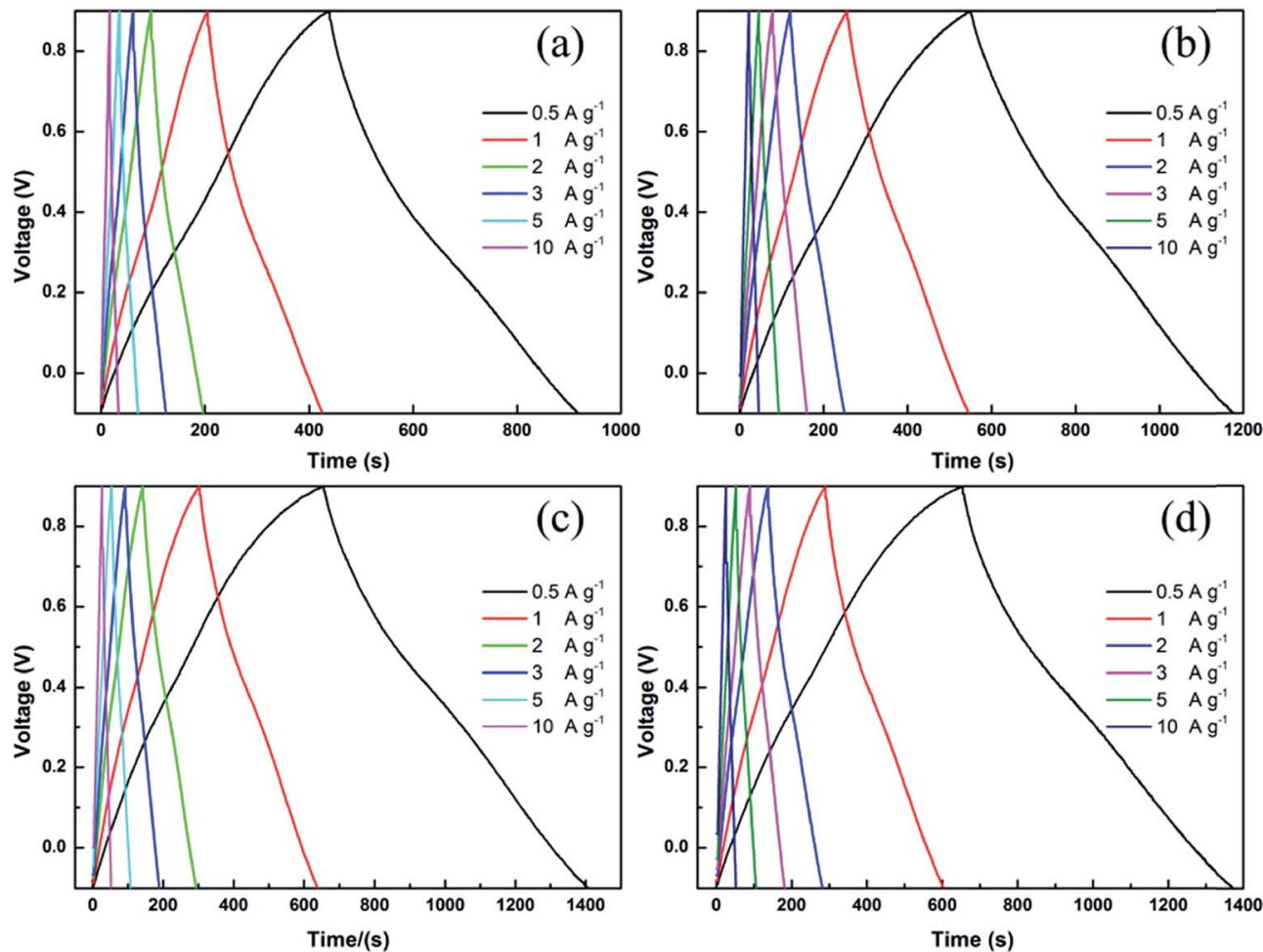

Fig. 7 The galvanostatic charge-discharge curves obtained at different current densities for the JC-1.5 (a), JC-2.5 (b), JC-3.5 (c) and JC-4.5 (d) samples.
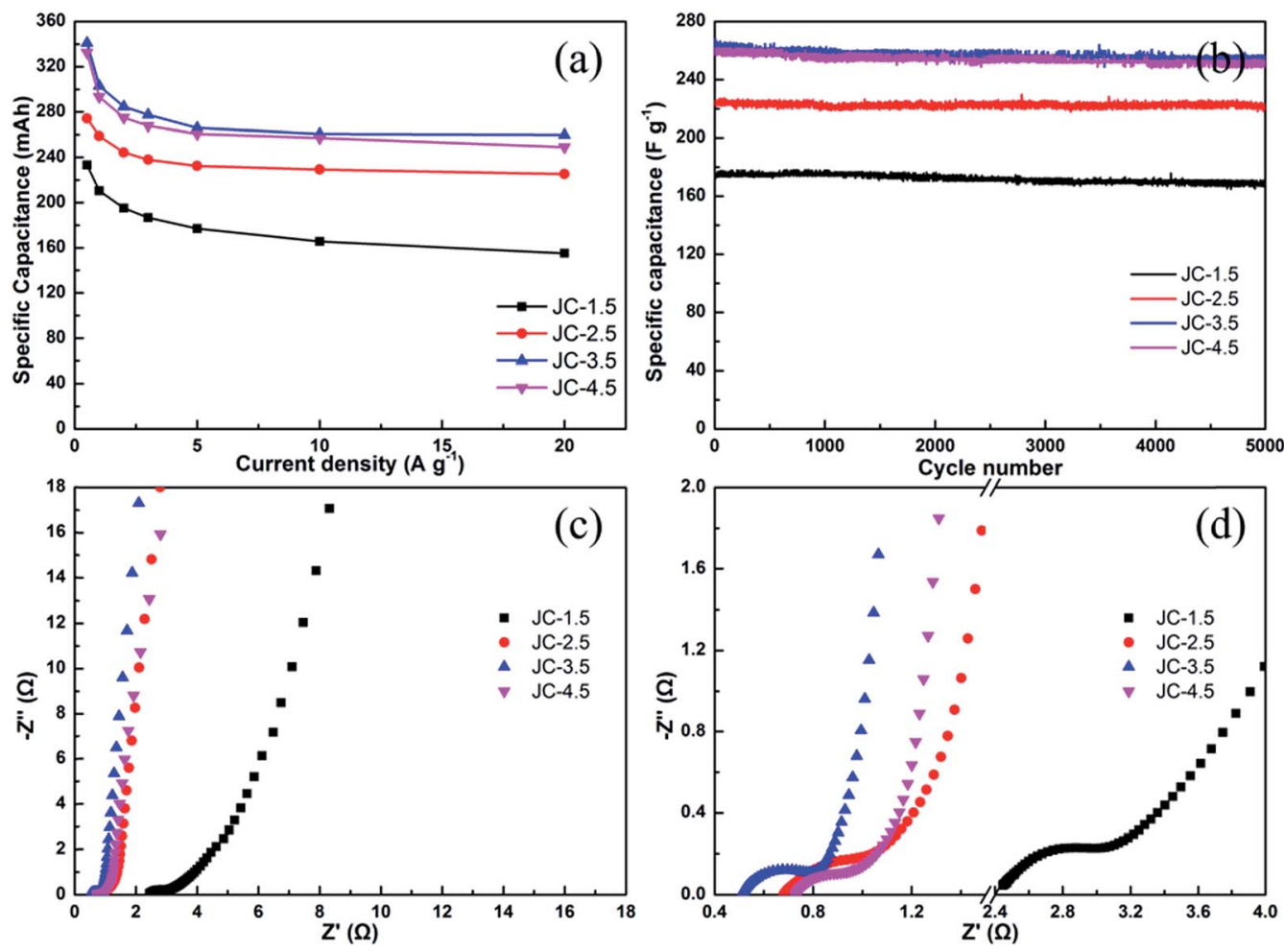

Fig. 8 The specific capacitance at various current densities (a), cycling performance at $5 \mathrm{~A} \mathrm{~g}^{-1}$ (b) and Nyquist plot (c and d) obtained for the JC$1.5, \mathrm{JC}-2.5, \mathrm{JC}-3.5$ and JC-4.5 samples. 
Table 3 A comparison of the properties of other biomass-derived materials with JC

\begin{tabular}{|c|c|c|c|c|}
\hline Source & $\begin{array}{l}\text { Specific surface } \\
\text { area }\left(\mathrm{m}^{2} \mathrm{~g}^{-1}\right)\end{array}$ & $\begin{array}{l}\text { Specific capacitance } \\
\text { (at current density) }\left(\mathrm{F} \mathrm{g}^{-1}\right)\end{array}$ & $\begin{array}{l}\text { Rate capability } \\
\text { (from } a \mathrm{~A} \mathrm{~g}^{-1} \text { to } b \mathrm{Ag}^{-1} \text { ) }\end{array}$ & Ref. \\
\hline Bamboo & 171.5 & 318 in $1 \mathrm{M} \mathrm{H}_{2} \mathrm{SO}_{4}(0.2)$ & $33.3 \%(0.2$ to 4.0$)$ & 20 \\
\hline Sawdust & - & 242 in $6 \mathrm{M} \mathrm{KOH} \mathrm{(0.5)}$ & $85.3 \%(0.5$ to 5$)$ & 22 \\
\hline Tobacco rods & 2115 & 286.6 in $1 \mathrm{M} \mathrm{H}_{2} \mathrm{SO}_{4}(0.5)$ & $74 \%(0.5$ to 30$)$ & 23 \\
\hline Pomelo peel & 2725 & 342 in $6 \mathrm{M} \mathrm{KOH}(0.2)$ & $62 \%(0.2$ to 20$)$ & 25 \\
\hline Tofu & 1202 & 418 in $6 \mathrm{M} \mathrm{KOH} \mathrm{(1)}$ & $>83.7 \%(1$ to 20$)$ & 36 \\
\hline Torreya grandis shell & 2101 & 290.5 in $6 \mathrm{M} \mathrm{КОН} \mathrm{(0.5)}$ & $62.6 \%(0.5$ to 20$)$ & 37 \\
\hline Winter jujube & 2286 & 341 in $1 \mathrm{M} \mathrm{H}_{2} \mathrm{SO}_{4}(0.5)$ & $76 \%(0.5$ to 20$)$ & This work \\
\hline
\end{tabular}

JC-3.5 had the smallest $R_{\mathrm{S}}$ values of $0.51 \Omega$ (the intercept of real axis), which means the smallest equivalent serial internal resistance. The curves show a semicircle in the high-frequency region, and the small semicircle diameter of JC-2.5, JC-3.5, and JC-4.5 indicate their small charge-transfer resistance. As with JC1.5, its poor EIS performance when compared with the other samples matches its poor specific capacitance and CV curve.

The practical application of JC-3.5 was evaluated in a twoelectrode system. Fig. 9a displays the $\mathrm{CV}$ curves obtained for JC-3.5 at different scan rates. The rectangular shape suggests its ideal electrochemical performance, which corresponds to the results obtained from the three-electrode system. EIS measurement reveals a quite small $R_{\mathrm{s}}$ value of $0.09 \Omega$ (Fig. 9b). The high slope of the Nyquist plot in the low-frequency region also demonstrates its outstanding ion diffusion capability. The GCD curves (Fig. 9c) at different current densities were also measured to characterize the specific capacitance. As shown in Fig. 9d, the specific capacitance of JC-3.5 was calculated to be $61.9 \mathrm{~F} \mathrm{~g}^{-1}$ at $0.1 \mathrm{~A} \mathrm{~g}^{-1}$ and it was still maintained at $79.2 \%$ $\left(49 \mathrm{~F} \mathrm{~g}^{-1}\right.$ ) at $5 \mathrm{~A} \mathrm{~g}^{-1}$. In addition, as shown in the Ragone plot (Fig. 9d), JC-3.5 possesses energy densities of 30.9 and $24.5 \mathrm{~W} \mathrm{~h} \mathrm{~kg}^{-1}$ at power densities of $133.5 \mathrm{~W} \mathrm{~kg}^{-1}$ and $8.9 \mathrm{~kW} \mathrm{~kg}^{-1}$, respectively.
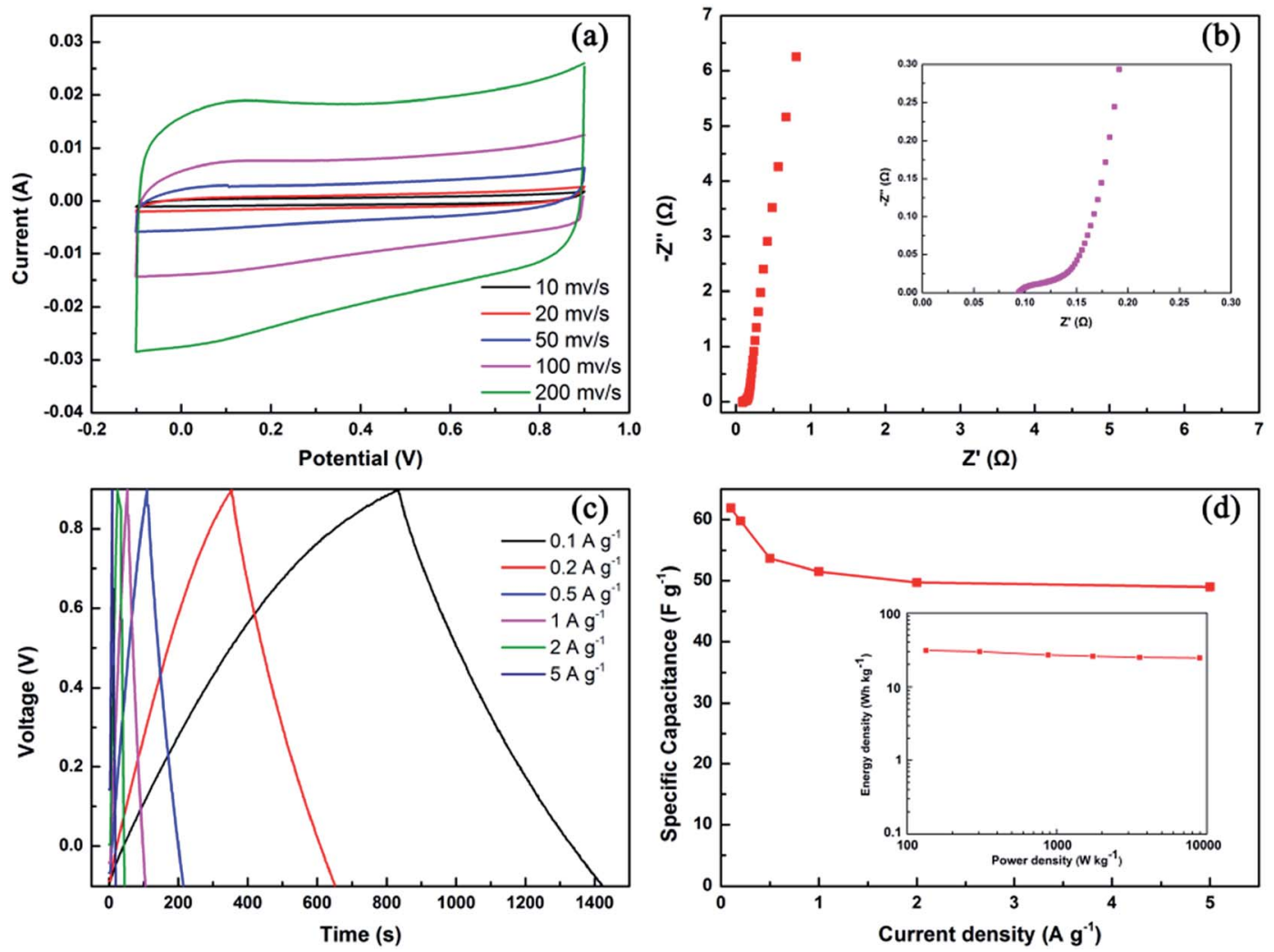

Fig. 9 The CV curves obtained for JC-3.5 at different scan rates (a), the Nyquist plot of JC-3.5 with the inset magnifying the high frequency region (b), galvanostatic charge-discharge curves at different current density of JC-3.5 (c) and specific capacitance at different current density with the inset showing the Ragone plot of JC-3.5 (d). 
Based on the above evaluation of the electrochemistry performance, JC-3.5 shows the most superior properties. First of all, suitable $\mathrm{KOH}$ consumption makes it possess the largest SSA and a hierarchical porous structure containing abundant micropores. This pore structure ensures excellent electrolyte contact and rapid ionic transportation, and thus enhances the charge storage density. Except for the excellent pore structure, the $\mathrm{O}$ and $\mathrm{N}$ containing functional groups determined using XPS can also increase the electrical conductivity and help the diffusion of ions and electrons. The self-doped heteroatoms on the surface may have undergone redox reactions to provide pseudo-capacitance behavior. As a supercapacitor electrode material, the JC performance is a combination of EDLC and faradaic pseudocapacitance, and possesses high capacitance, good rate performance, and excellent cycling stability.

\section{Conclusions}

In this work, we have reported a winter-jujube-derived carbon material (JC) prepared via pre-carbonization and $\mathrm{KOH}-$ activation. The synthesized JC samples possess abundant selfdoped heteroatoms and hierarchically porous structures (the co-existence of micro-, meso-, and macropores). The samples prepared with different $\mathrm{KOH}$ consumption possess different properties. In these samples, JC-3.5 with a $\mathrm{KOH}$ to carbon weight ratio of $3.5: 1$ had an ultra-high SSA of $2286.2 \mathrm{~cm}^{3} \mathrm{~g}^{-1}$. JC-3.5 possessed a high capacitance up to $341 \mathrm{~F} \mathrm{~g}^{-1}$ at $0.5 \mathrm{~A} \mathrm{~g}^{-1}$. The presence of abundant self-doped heteroatoms $\mathrm{O}$ and $\mathrm{N}$ made a huge contribution. Besides the high specific capacitance, it also has good rate performance $(76 \%$ capacitance retained when the current was increased to $20 \mathrm{~A} \mathrm{~g}^{-1}$ from $\left.0.5 \mathrm{~A} \mathrm{~g}^{-1}\right)$. As for its cycling stability, there was only a $4.5 \%$ capacitance loss after 5000 cycles at $5 \mathrm{~A} \mathrm{~g}^{-1}$. Besides, the JC-3.5based symmetric supercapacitor device possessed an energy density of $30.9 \mathrm{~kW} \mathrm{~h}^{-1}$ at $0.1 \mathrm{~A} \mathrm{~g}^{-1}$ and power density of $8.9 \mathrm{~kW}$ at $5 \mathrm{~A} \mathrm{~g}^{-1}$. In summary, as a renewable green resource, winterjujube-derived carbon material is a promising candidate for use as a supercapacitor electrode material.

\section{Conflicts of interest}

There are no conflicts to declare.

\section{Acknowledgements}

The authors greatly appreciate the financial support from the National Natural Science Foundation of China (Project No. 21476013).

\section{References}

1 P. Poizot, S. Laruelle, S. Grugeon, et al., Nano-sized transition-metal oxides as negative-electrode materials for lithium-ion batteries, Nature, 2000, 407(6803), 496-499.

2 L. Xu, Y. Hu, H. Zhang, et al., Confined synthesis of $\mathrm{FeS}_{2}$ nanoparticles encapsulated in carbon nanotube hybrids for ultrastable lithium-ion batteries, ACS Sustainable Chem. Eng., 2016, 4(8), 4251-4255.

3 T. Jiang, R. Zhang, Q. Yin, et al., Morphology, composition and electrochemistry of a nano-porous silicon versus bulk silicon anode for lithium-ion batteries, J. Mater. Sci., 2016, 1-8.

4 B. Qiu, M. Xing and J. Zhang, Mesoporous TiO2 nanocrystals grown in situ on graphene aerogels for high photocatalysis and lithium-ion batteries, J. Am. Chem. Soc., 2014, 136(16), 5852-5855.

5 E. Yoo, J. Kim, E. Hosono, et al., Large reversible Li storage of graphene nanosheet families for use in rechargeable lithium ion batteries, Nano Lett., 2008, 8(8), 2277-2282.

6 X. Yang, C. Wei and G. Zhang, Activated carbon aerogels with developed mesoporosity as high-rate anodes in lithium-ion batteries, J. Mater. Sci., 2016, 51(11), 5565-5571.

7 C. Guan, J. Liu, Y. Wang, et al., Iron oxide-decorated carbon for supercapacitor anodes with ultrahigh energy density and outstanding cycling stability, ACS Nano, 2015, 9(5), 51985207.

$8 \mathrm{~W} . \mathrm{Lu}, \mathrm{M} . \mathrm{Liu}, \mathrm{L}$. Miao, et al., Nitrogen-containing ultramicroporous carbon nanospheres for high performance supercapacitor electrodes, Electrochim. Acta, 2016, 205, 132-141.

9 C. Liu, Z. Yu, D. Neff, et al., Graphene-based supercapacitor with an ultrahigh energy density, Nano Lett., 2010, 10(12), 4863-4868.

10 Q. Ke, Y. Liao, S. Yao, et al., A three-dimensional $\mathrm{TiO}_{2} /$ graphene porous composite with nano-carbon deposition for supercapacitor, J. Mater. Sci., 2016, 51(4), 2008-2016.

$11 \mathrm{~J}$. Tang, Y. Ge, J. Shen, et al., Facile synthesis of $\mathrm{CuCo}_{2} \mathrm{~S}_{4}$ as a novel electrode material for ultrahigh supercapacitor performance, Chem. Commun., 2016, 52(7), 1509-1512.

12 X. Cao, Y. Shi, W. Shi, et al., Preparation of novel 3D graphene networks for supercapacitor applications, Small, 2011, 7(22), 3163-3168.

13 G. Wang, H. Wang, X. Lu, et al., Solid-State Supercapacitor Based on Activated Carbon Cloths Exhibits Excellent Rate Capability, Adv. Mater., 2014, 26(17), 2676-2682.

14 X. Lu, M. Yu, T. Zhai, et al., High energy density asymmetric quasi-solid-state supercapacitor based on porous vanadium nitride nanowire anode, Nano Lett., 2013, 13(6), 2628-2633.

15 L. B. Kong, J. Zhang, J. J. An, et al., MWNTs/PANI composite materials prepared by in situ chemical oxidative polymerization for supercapacitor electrode, J. Mater. Sci., 2008, 43(10), 3664-3669.

16 Y. Zhu, S. Murali, M. D. Stoller, et al., Carbon-based supercapacitors produced by activation of graphene, science, 2011, 332(6037), 1537-1541.

17 B. Conway, Electrochemical Supercapacitors: Sci-entific Fundamentals and Technological Applications. KluwerPlenum, 1999.

$18 \mathrm{~J}$. $\mathrm{Mu}$, B. Chen, Z. Guo, et al., Highly dispersed $\mathrm{Fe}_{3} \mathrm{O}_{4}$ nanosheets on one-dimensional carbon nanofibers: Synthesis, formation mechanism, and electrochemical performance as supercapacitor electrode materials, Nanoscale, 2011, 3(12), 5034-5040. 
19 K. Zhang, L. L. Zhang, X. S. Zhao, et al., Graphene/ polyaniline nanofiber composites as supercapacitor electrodes, Chem. Mater., 2010, 22(4), 1392-1401.

20 H. Chen, D. Liu, Z. Shen, et al., Functional Biomass Carbons with Hierarchical Porous Structure for Supercapacitor Electrode Materials, Electrochim. Acta, 2015, 180, 241-251.

21 X. He, P. Ling, J. Qiu, et al., Efficient preparation of biomassbased mesoporous carbons for supercapacitors with both high energy density and high power density, J. Power Sources, 2013, 240(1), 109-113.

22 C. Li, J. Yu, C. Xiao, et al., Microporous carbons with threedimensional interconnected macropores based on corn stigmas for advanced supercapacitors, J. Mater. Sci., 2017, 52(5), 2816-2824.

23 Y. Q. Zhao, M. Lu, P. Y. Tao, et al., Hierarchically porous and heteroatom doped carbon derived from tobacco rods for supercapacitors, J. Power Sources, 2016, 307, 391-400.

24 Y. Huang, Y. Liu, G. Zhao, et al., Sustainable activated carbon fiber from sawdust by reactivation for high-performance supercapacitors, J. Mater. Sci., 2017, 52(1), 478-488.

25 Q. Liang, L. Ye, Z. H. Huang, et al., A honeycomb-like porous carbon derived from pomelo peel for use in highperformance supercapacitors, Nanoscale, 2014, 6(22), 13831.

26 X. Wei, Y. Gao, W. Xu, et al., Composite of Macroporous Carbon with Honeycomb-Like Structure from Mollusc Shell and $\mathrm{NiCo}_{2} \mathrm{O}_{4}$ Nanowires for High-Performance Supercapacitor, ACS Appl. Mater. Interfaces, 2014, 6(21), 19416.

27 W. Huang, H. Zhang, Y. Huang, et al., Hierarchical porous carbon obtained from animal bone and evaluation in electric double-layer capacitors, Carbon, 2011, 49(3), 838843.

28 Q. Wang, J. Yan, Y. Wang, et al., Three-dimensional flowerlike and hierarchical porous carbon materials as high-rate performance electrodes for supercapacitors, Carbon, 2014, 67(2), 119-127.

29 G. Y. Xu, J. P. Han, D. Bing, et al., Biomass-derived porous carbon materials with sulfur and nitrogen dual-doping for energy storage, Green Chem., 2015, 17(3), 1668-1674.

30 M. Sevilla and R. Mokaya, Energy storage applications of activated carbons: supercapacitors and hydrogen storage, Energy Environ. Sci., 2014, 7(4), 1250-1280.

31 Y. Zhu, S. Murali, M. D. Stoller, et al., Carbon-based supercapacitors produced by activation of graphene, Science, 2011, 332(6037), 1537.

32 R. J. Nemanich and S. A. Solin, First- and second-order Raman scattering from finite-size crystals of graphite, Phys. Rev. B: Condens. Matter Mater. Phys., 1979, 20(2), 392-401.

33 M. Polovina, B. Babić, B. Kaluderović, et al., Surface characterization of oxidized activated carbon cloth, Carbon, 1997, 35(8), 1047-1052.

34 Y. Huang, J. He, Y. Luan, et al., Promising biomass-derived hierarchical porous carbon material for high performance supercapacitor, RSC Adv., 2017, 7(17), 10385-10390.

35 G. Ma, F. Ran, H. Peng, et al., Nitrogen-doped porous carbon obtained via one-step carbonizing biowaste soybean curd residue for supercapacitor applications, RSC Adv., 2015, 5(101), 83129-83138.

36 T. Ouyang, K. Cheng, Y. Gao, et al., Molten salt synthesis of nitrogen doped porous carbon: a new preparation methodology for high-volumetric capacitance electrode materials, J. Mater. Chem. A, 2016, 4(25), 9832-9843.

37 H. Xuan, G. Lin, F. Wang, et al., Preparation of biomassactivated porous carbons derived from torreya grandis shell for high-performance supercapacitor, J. Solid State Electrochem., 2017, 1-9. 